\title{
Metastatic Digestive System Neuroendocrine Carcinoma
}

National Cancer Institute

\section{Source}

National Cancer Institute. Metastatic Digestive System Neuroendocrine Carcinoma. NCI Thesaurus. Code C155936.

A neuroendocrine carcinoma that arises from any part of the digestive system and has metastasized to another anatomic site. 